\title{
Regional coronary endothelial dysfunction is related to local epicardial fat in HIV+ patients
}

\author{
Allison Hays ${ }^{1 *}$, Micaela lantorno ${ }^{1}$, Michael Schär ${ }^{2}$, Sahar Soleimanifard ${ }^{1}$, Richard Moore ${ }^{1}$, Gary Gerstenblith${ }^{1}$, \\ Robert Weiss ${ }^{1}$
}

From 19th Annual SCMR Scientific Sessions

Los Angeles, CA, USA. 27-30 January 2016

\section{Background}

With improved survival resulting from anti-retroviral therapies, accelerated coronary artery disease (CAD) has become an important cause of significant disability and premature death in HIV-infected patients. HIV+ people often accumulate epicardial adipose tissue (EAT), a metabolically-active visceral fat capable of releasing inflammatory adipokines that could contribute to CAD through local paracrine actions. We tested the hypothesis that abnormal coronary endothelial function (CEF), an early marker of atherosclerosis and predictor of CAD events, is related to the amount of local pericoronary EAT in HIV+ patients.

\section{Methods}

We studied $30 \mathrm{HIV}+$ subjects, 16 with no CAD ("HIVnoCAD", 0 Calcium score by CT, mean age: $53 \pm$ 3 years, 22 RCA segments) and 14 with known CAD ("HIV CAD", $58 \pm 4$ years, 19 segments). To measure CEF, coronary MRI was performed before and during isometric handgrip exercise (IHE), an endothelialdependent stressor and \% coronary cross-sectional area (CSA) change was quantified. MRI for coronary EAT local area and thickness in the atrioventricular groove was performed at the same imaging plane as that used for CEF. All data are expressed: as mean \pm SEM.

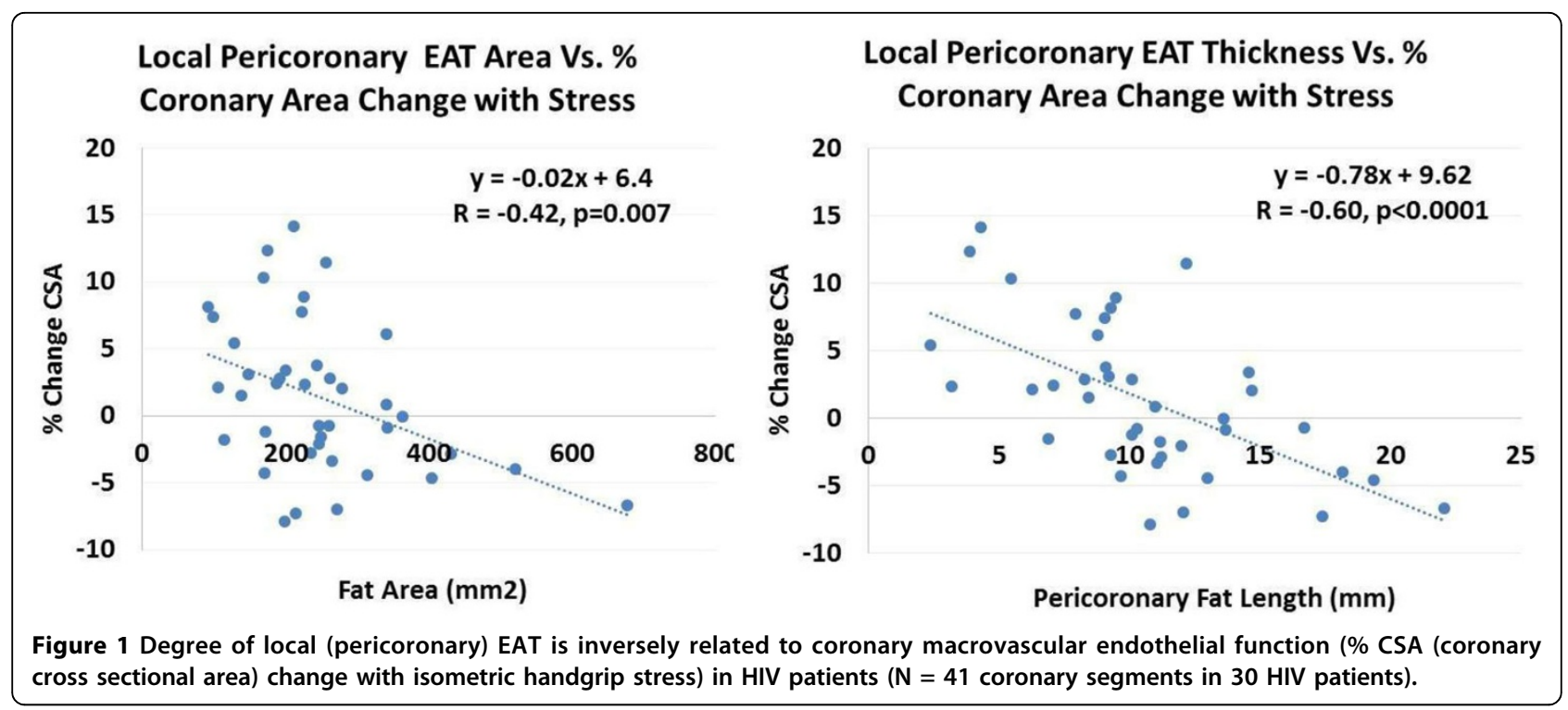

${ }^{1}$ Medicine, Johns Hopkins, Clarksville, MD, USA

Full list of author information is available at the end of the article

(0) 2016 Hays et al. This is an Open Access article distributed under the terms of the Creative Commons Attribution License (http:// creativecommons.org/licenses/by/4.0), which permits unrestricted use, distribution, and reproduction in any medium, provided the original work is properly cited. The Creative Commons Public Domain Dedication waiver (http://creativecommons.org/publicdomain/ zero/1.0/) applies to the data made available in this article, unless otherwise stated. 


\section{Results}

In HIVnoCAD subjects, the IHE-induced \% change CSA was significantly greater than in HIV CAD subjects $(3.7 \pm$ $1.2 \%$ v. $-1.0 \pm 1.0 \%, \mathrm{p}=0.004$ ) and mean pericoronary EAT area was lower, $209 \pm 16 \mathrm{~mm}^{2}$ v. $293 \pm 31 \mathrm{~mm}^{2}, \mathrm{p}=$ 0.02 ). There was a significant inverse relationship between $\%$ CSA change with IHE and both local fat area $(R=-0.42$, $\mathrm{p}=0.007)$ and fat thickness $(\mathrm{R}=-0.60, \mathrm{p}<0.0001)$ for all HIV subjects.

\section{Conclusions}

The extent of local coronary EAT is significantly related to coronary endothelial dysfunction and thus may be an important contributor to coronary disease in HIV+ patients. Interventions to reduce this component of visceral adipose tissue may favorably limit the otherwise accelerated coronary atherosclerosis in this important patient population.

\section{Authors' details}

${ }^{1}$ Medicine, Johns Hopkins, Clarksville, MD, USA. ${ }^{2}$ Radiology, Johns Hopkins, Baltimore, MD, USA.

Published: 27 January 2016 